\title{
Effects of amount of reward on acquisition of a black-white discrimination*
}

\author{
RICHARD S. WEISINGER, LORNE F. PARKER \\ and ROBERT C. BOLLES \\ University of Washington, Seattle, Wash. 98105
}

Two experiments demonstrated that rats learn a black-white discrimination more rapidly if they are trained with a larger amount of reward (AOR). This AOR enhancement of performance was found over a variety of pretraining conditions, indicating that the effect has some generality.

One of the paradoxes in the incentive motivation literature is that the amount of reward (AOR) seems to affect performance only in certain experimental situations. In simple situations, such as runways, rats consistently perform better if a greater AOR is made contingent upon the response (e.g., Crespi, 1942). In discrimination learning, however, inconsistent effects of AOR have been reported. Reynolds (1949), Greene (1953), and McKelvey (1956) all found the acquisition of a black-white discrimination to be independent of AOR. Schrier (1956) and Waller (1968), on the other hand, found that increased AOR improved performance in the black-white discrimination situation, and both authors attributed the failures of earlier investigators in finding AOR effects in discrimination learning to methodological differences.

The purpose of the present experiments is to show that the AOR parameter does affect the acquisition of black-white discrimination, and that this effect exists over a considerable range and variety of experimental parameters.

\section{EXPERIMENT I}

Waller (1968), who reported an AOR effect, pretrained his animals for an extended period of time and gave them considerable experience with both the goalbox cues and the different amounts of reinforcement. Reynolds (1949) and McKelvey (1956), who reported no AOR effect, gave little pretraining. Schrier (1956) obtained an AOR effect, but only during the second 20 trials of training, perhaps because after 20 trials the Ss had received sufficient experience with the relevant parameters. Experiment I tests the hypothesis implied by these differences, namely that the AOR effect in black-white discrimination learning requires $S$ to have prior experience with differential amounts of food and/or the black-white cues.

Subjects

\section{Method}

The Ss were 64 120-day-old naive male Wistar rats.

*Supported by Research Grant GB-20801 from the National Science Foundation.
Throughout the experiment, Ss were individually housed and maintained by food deprivation at $80 \%$ of ad lib body weight.

\section{Apparatus}

The pretraining apparatus consisted of a set of six boxes measuring $25 \times 25 \times 15 \mathrm{~cm}$ high. Two were painted black, two were painted white, and two were unpainted plywood. A straight gray runway, $90 \mathrm{~cm}$ long and with a guillotine door, was used to habituate the Ss to being handled, to doors, and to running into food boxes.

The discrimination apparatus resembled that used by Grice (1948), Reynolds (1949), and Schrier (1956). A gray startbox, measuring $10 \times 25 \mathrm{~cm}$, led directly to a $30-\mathrm{cm}$-long choice area which varied in width from $10 \mathrm{~cm}$ at the startbox to $23 \mathrm{~cm}$ at the runways. The runways were each $10 \times 32 \mathrm{~cm}$ long and were painted either black or white to match the color of the goalboxes. Dropping doors separated the startbox from the choice area, and the runways from the goalboxes. Alternating alley positions was accomplished by moving the start and choice parts of the apparatus back and forth in front of three runways painted black and white and black. Preliminary investigation indicated that Ss showed some initial preference for black; therefore, the white cue was made positive for all Ss.

\section{Procedure}

Prior to discrimination training, four groups of animals were subjected to pretraining procedures that combined the presence or absence of the black-white discriminative cues with differential AOR vs no reinforcement during pretraining. Specifically, the four groups were run under the following conditions: (1) Group $\overline{\mathrm{C}}-\overline{\mathrm{F}}$ was pretrained in the neutral boxes, i.e., in the absence of black-white apparatus cues, and no food; (2) Group $\bar{C}-F$, in neutral boxes with alternating one and four food pellets; (3) Group $\mathrm{C}-\overrightarrow{\mathrm{F}}$, in alternating black and white pretraining boxes with no food; and (4) Group C-F, in black and white boxes with one pellet of food in the black box and four pellets of food in the white box. The food in each case was .45 -mg Noyes pellets.

All Ss were pretrained for 5 days with eight trials per day, one trial consisting of $S$ being placed in a pretraining box for $1 \mathrm{~min}$ before being transferred to another box. Following pretraining, each group was trained in the Grice apparatus eight trials per day until a criterion of nine consecutively correct responses was met. Half of each group received one pellet for a correct response, while the other half received four pellets. The starting side, left or right for the positive white alley, was randomized. The Ss were run blind by an E with no knowledge of S's pretraining conditions.

\section{Results}

An analysis of variance applied to the number of trials required to meet criterion indicated that the rate of acquisition was enhanced by pretraining with the black and white boxes $(\mathrm{F}=6.1$, $\mathrm{df}=1,56, \mathrm{p}<.05)$, but not by pretraining with the different AOR conditions $(F \geqslant 1.0)$. Furthermore, Ss trained with four pellets learned faster than those trained with one pellet $(F=5.45, \mathrm{df}=1,56, \mathrm{p}<.05)$. None of the interactions was significant. The mean of each group is given in Table 1.

These findings demonstrate that the AOR effect in 
Table 1

Mean Trials to Criterion of Rats Given Different Amounts of Pretraining and Reward in Discrimination Training

\begin{tabular}{lcc} 
& \multicolumn{2}{c}{ Training Conditions } \\
\cline { 2 - 3 } $\begin{array}{c}\text { Pretraining } \\
\text { Conditions }\end{array}$ & $\begin{array}{c}\text { One } \\
\text { Pellet }\end{array}$ & $\begin{array}{c}\text { Four } \\
\text { Pellets }\end{array}$ \\
\hline Experiment I & & \\
C-F & 11.0 & 7.1 \\
C- $\bar{F}$ & 11.8 & 6.1 \\
$\bar{C}-\bar{F}$ & 22.7 & 11.7 \\
$\bar{C}-\bar{F}$ & 14.0 & 11.7 \\
Experiment II & 18.0 & 7.1 \\
Handled & - & 8.3 \\
Not Handled & & \\
\hline
\end{tabular}

discrimination learning has some generality over a number of specific pretraining conditions. Although prior experience with the black-white cues served to facilitate learning, the discrimination was readily learned by all the groups. Hence, none of the pretraining parameters appear to be a necessary condition for the AOR effect to occur in the black-white discrimination situation.

\section{EXPERIMENT II}

Experiment II was conducted to determine whether the AOR effect could be obtained in the black-white discrimination situation after Ss had received minimal pretraining experience.

\section{Method}

The Ss were 24 male Wistar rats, of which half received 40 pretraining trials under the $\overline{\mathrm{C}}-\overline{\mathrm{F}}$ conditions described in Experiment I. The remaining Ss were given no exposure to the experimental apparatus and were maintained in their home cages until run in the Grice apparatus at $80 \%$ of ad lib body weight. Half of each group received one pellet for a correct response, while the other half received four pellets. Discrimination training was conducted according to the procedure described in Experiment I.

\section{Results}

Table 1 shows the mean number of trials each group required to reach learning criterion. As indicated in Table 1, four animals in the no-handling and one-pellet subgroup failed to meet the acquisition criterion. Hence, Mann-Whitney tests were employed to reveal that the four-pellet groups learned significantly faster than the one-pellet groups. A t test comparing the two large AOR groups revealed no significant differences $(t=.13$, $\mathrm{df}=10$ ). It $:$ is apparent from these findings that no pretraining and minimal AOR experience in training lead to poor performance. Furthermore, the AOR effect on performance occurs in the absence of any pretraining.

\section{GENERAL DISCUSSION}

The most significant finding in both experiments was that $\mathrm{S} s$ given a large amount of reward consistently performed better in the black-white discrimination situation than did Ss given a small amount of reward. Such pretraining conditions as familiarity with black-white cues and handling were found to enhance performance significantly, but were not necessary for AOR facilitation of learning. The generality of this AOR effect is surprising in light of the equivocal effects of the AOR parameter reported in prior studies. They are surprising also in that the experimental manipulations which had been anticipated to interact with the AOR variable failed to do so. Thus, the AOR effect in discrimination learning appears to be rather general, as in runway performance (Crespi, 1942), but perhaps subject to subtle parameters that are not readily apparent in the literature.

The results of Experiment II, which tested the effects of handling on performance, suggest that handling during pretraining is important only when a small AOR is used. The Ss given no handling and tested with a small AOR performed poorly, if at all. Both handled and nonhandled Ss tested with a large AOR, on the other hand, performed well and were not reliably different from each other. These results suggest that perhaps the poorer performance of the low AOR Ss can be attributed to an emotional factor that is lessened by either handling or a large AOR. Thus, perhaps Ss perform well if given either a large AOR or habituation to handling. In the absence of such emotion-habituating procedures, the rat is likely to perform poorly in the discrimination situation.

Such an interpretation indicates that the AOR variable does not act as a motivator in the traditional sense. Rather, it may serve to make the situation more discriminable by eliciting behaviors that are incompatible with emotional stress (i,e., eating behavior). The larger the reward, the more eating behavior in the goalbox, and the more optimal the arousal level of $\mathrm{S}$ for learning the discrimination. The effect of AOR, then, would be much the same as hibituation to handling and familiarization with apparatus cues-a reduction in suspiciousness of the experimental situation which may lead to a more optimal level of arousal in the discrimination situation.

\section{REFERENCES}

Crespi, L. P. Quantative variation of incentive and performance in the white rat. American Journal of Psychology, 1942, 55, 467-517.

Greene, J. E. Magnitude of reward and acquisition of a black-white discrimination habit. Journal of Experimental Psychology, 1953, 46, 113-119.

Grice, $G$. R. The relation of secondary reinforcement to delayed reward in visual discrimination learning. Journal of Experimental Psychology, 1948, 38, 1-16.

McKelvey, $R$. K. The relationship between training methods and reward variables in brightness discrimination learning. Journal of Comparative \& Physiological Psychology, 1956, 49, 485-491.

Reynolds, B. The acquisition of a black-white discrimination habit under two levels of reinforcement. Journal of Experimental Psychology, 1949, 39, 760-769.

Schrier, A. M. Amount of incentive and performance on a black-white discrimination problem. Journal of Comparative \& Physiological Psychology, 1956, 49, 123-125.

Waller, T. G. Effects of magnitude of reward in spatial and brightness discrimination tasks. Journal of Comparative \& Physiological Psychology, 1968, 66, 122-127.

(Received for publication A pril 9, 1973.) 